Jonathan E. Leightner*

\section{Estimates of the Inflation versus Unemployment Tradeoff that are not Model Dependent}

\begin{abstract}
For governments who want to improve their economies via fiscal, monetary, trade or exchange rate policies, the tradeoff between the inflation rate and the unemployment rate is extremely important. This tradeoff has become known as the Phillips curve. Among economists there is no consensus on how to model and estimate the Phillips curve. Ideally, all the factors that could affect the Aggregate Supply and Aggregate Demand curves should be included in the model including exchange rates, transportation costs, infrastructure, weather, income distribution, etc. No researcher has created a model that could not be criticized for omitting some important variables. This paper use Bi-Directional Reiterative Truncated Least Squares, a statistical technique that solves the omitted variables problem, to estimate the tradeoff between inflation and unemployment for 34 countries between 2002 and 2017. I find that this tradeoff varies noticeably from country to country in a given year, but that many of these tradeoffs move in the same direction over time. This common direction of movement implies that the international context for the vast majority of the countries studied is affecting the inflation versus unemployment tradeoff.
\end{abstract}

Key words: Phillips Curve, Inflation, Unemployment, Omitted Variables, Trade-off

JEL codes: E60 and J21

\section{Introduction}

In addition to increasing growth, most governments want to reduce unemployment and keep inflation at low and
${ }^{*}$ Hull College of Business, Augusta, Georgia,

United States

E-mail:

jleightn@augusta.edu 
stable levels. However, most of the government's tools for achieving the inflation and unemployment goals - fiscal policy, monetary policy, trade policy, and exchange rate policy - tend to help one goal while hurting the other. Thus these governments are faced with hard choices about how far to push its economic policies. One key to making optimal decisions in this context is to know the tradeoff between inflation and unemployment. This tradeoff has become known as the Phillips Curve. Unfortunately, the Phillips Curve is instable, shifting often. To use traditional statistical methods to estimate the Phillips Curve would involve creating a structural model that includes every force that can affect inflation, unemployment and their tradeoff. After every equation in this model was correctly specified and estimated the model could be solved for the inflation and unemployment tradeoff. However, this is a daunting task that could involve hundreds of equations - equations that different economists would model in different ways. Consensus would be impossible.

This paper uses a statistical technique that produces a separate slope estimate for every observation where variations in these slope estimates are due to omitted variables. This technique makes it possible to estimate the tradeoff between inflation and unemployment without having to construct, justify, and estimate an entire structural model. This technique produces total derivate estimates that show all the ways that unemployment and inflation are related; in contrast to partial derivatives that show the effects of unemployment on inflation holding all other variables constant. In other words, this technique produces exactly the type of estimate that governments need to know. Finally the data requirements for this technique are minimal - only data on the inflation rate and the unemployment rate are needed. This technique is the most efficient way to give governments the information that they need on the tradeoff between unemployment and inflation.

The remainder of this paper is organized as follows. Section II explains the technique used and how it will be applied to estimating the Phillips Curve. Section III presents the empirical results. Section IV concludes.

\section{Data and Estimation Issues}

I calculate estimates of the percentage change in inflation due to a one percentage change in unemployment for all the OECD countries for which data was available on OECD.Stat for 2002 to 2017. The inflation rate was calculated as the percentage change in the consumer price index [inflation rate for $2002=\left(\left(\mathrm{CPI}_{2002}\right.\right.$ $\left.\left.\left.\left.-\mathrm{CPI}_{2001}\right) / \mathrm{CPI}_{2001}\right) \times 100\right)\right]$. The one exception to this method of calculating the inflation rate was for 2017; because OECD. Stat did not list CPI data for 2017 as 
of the writing of this paper, I used the OECD's calculation of the inflation rate for 2017. The number of unemployed people (of all ages, genders, and durations of unemployment) was divided by the number in the labor force and multiplied by 100 to obtain the unemployment rate.

To use traditional regression procedures to estimate the percentage change in the inflation rate due to a one percent drop in unemployment, $d$ (inflation rate)/ $d$ (unemployment rate), a researcher would have to build a structural model that included all the forces that affect inflation and unemployment. Forces that should be modeled include government spending and taxing, monetary policy, the prices of imports and exports, exchange rates, the productivity of labor and capital, weather's effects on crop prices, transportation costs, consumer attitudes towards debt, etc. Paul Samuelson and Robert Solow ended their 1960 article that popularized the Phillip's curve with the following disclaimer:

"We have not here entered upon the important question of what feasible institutional reforms might be introduced to lessen the degree of disharmony between full employment and price stability. These could of course involve such wide-ranging issues as direct price and wage controls, antiunion and antitrust legislation, and a host of other measures hopefully designed to move the American Phillip's curve downward and to the left."

Samuelson and Solow are correct - an adequate model of the Phillip's curve also should model institutional considerations that affect employment and inflation. Instead of modelling all of the above issues, most of the Phillip's curve literature has struggled almost exclusively with how to model inflation expectations (for example, Lakić, Šehović, and Drašković (2016) focus primarily on keeping inflation expectations low). Clearly inflation expectations are important to the Phillip's curve. However, if, as the next paragraph shows, it is so hard to model one thing - inflation expectations - that shifts the Phillip's curve; it is indeed impossible to adequately model all of the forces that could affect the inflation/ unemployment tradeoff in a way that would be acceptable to all economists.

Roberts (1995) argues that inflation expectations are crucial to estimates of the Phillips curve and that the best way to find these expectations is to use surveys. In contrast most subsequent studies of the Phillips curve do not go to the trouble of finding inflation expectations via surveys. Debelle and Laxton (1997) show that a non-linear curve fits the relationship between unemployment and inflation better than a straight line. Again, this revelation is ignored by most subsequent studies. Akerlof et al (2000) argue that how actors use inflation expectations is more important than how they formulate those expectations. For example when inflation is low, actors might just ignore the prospect of future inflation. Mankiw 
and Reis (2002) argue that information might be "stickier" than prices and they suggest a reformulation of the Phillips curve accordingly. However, again, most subsequent researchers do not attempt to model the rate of diffusion of information. There is a heated debate in the literature on whether inflation expectations are forward or backward looking, and thus on how best to model them; for examples, see Rudd and Whelan (2005) and Gali, Gertler, and Lopez-Salido (2005). There are also some papers which explicitly consider monetary policy when estimating Phillips curves; for examples see Cogley and Sbordone (2008) and Dolado, Maria-Dolores, and Naveira (2005).

None of the literature considers all the possible factors that can move a country along a given Phillips curve and all the factors that could shift that Phillips curve. Anything that can shift an Aggregate Demand curve would move along a given Phillips curve including changes in fiscal policy, monetary policy, business expectations (of profits, inflation, growth, etc.), credit, consumer attitudes towards debt, income distribution, export and import prices, exchange rates, transportation costs, trade agreements, etc. Furthermore, the interplay of these factors would affect the shape of the Phillips curve. Forces that can shift the short run Aggregate Supply curve would shift the Phillips curve. These factors include tax systems (who is taxed and at what level), technology, cost of inputs (including wage rates and the cost of imported inputs which again introduces the exchange rate and all of its determinants), transportation costs, and changes in the environment (weather, infrastructure, institutions, etc.). At the very least, using traditional regression analysis to estimate the Phillips curve should require the modelling and inclusion of all the forces that could shift the short run Aggregate Supply curve. Once all these forces are model and each curve in it estimated, then a reduced form equation could be derived for the relationship between inflation and unemployment. The resulting equation would be a total derivative. Directly estimating this total derivative using traditional regression techniques would produce biased and inconsistent estimates because it would be plagued with omitted variable bias.

Fortunately there are ways to estimate total derivatives that capture the effects of omitted variables without having to construct and estimate entire structural models (Inoue, Lafaye de Micheaux, and Leightner, 2018). If a researcher estimates equation (1) while ignoring equation (2), the resulting estimate of $\beta_{1}$ is a constant when in truth $\beta_{1}$ varies with $\mathrm{q}_{\mathrm{t}}{ }^{1}$ This constitutes an "omitted variable" problem where " $\mathrm{q}_{t}$ " represents the combined influence of all omitted variables plus any random variation in $\beta_{1}$ itself.

1 The $\alpha_{s}$ and $\beta_{s}$ are coefficients to be estimated, $\mathrm{Y}$ is the dependent variable, $\mathrm{X}$ is the explanatory variable, and $u$ is random error. 
$\mathrm{Y}_{\mathrm{t}}=\alpha_{0}+\beta_{1} \mathrm{X}_{\mathrm{t}}+u$

$\beta_{1}=\alpha_{1}+\alpha_{2} q_{t}$

One convenient way to model the omitted variable problem is to combine equations (1) and (2) to produce equation (3).

$Y_{t}=a_{0}+a_{1} X_{t}+a_{2} X_{t} q_{t}+u_{t}$

Equation (7) can be derived from equation (3) as shown below (Leightner, 2015, 2010a, and 2010b; Inoue et al, 2018; and Leightner and Inoue 2012b).

$$
\begin{array}{ll}
\left(d \mathrm{Y}_{\mathrm{t}} / d \mathrm{X}_{\mathrm{t}}\right)^{\text {True }}=\alpha_{1}+\alpha_{2} \mathrm{q}_{\mathrm{t}} & \text { Derivative of (3) } \\
\mathrm{Y}_{\mathrm{t}} / \mathrm{X}_{\mathrm{t}}=\alpha_{0} / \mathrm{X}_{\mathrm{t}}+\alpha_{1}+\alpha_{2} \mathrm{q}_{\mathrm{t}}+u_{t} / \mathrm{X}_{\mathrm{t}} & \text { (3) divided by } \mathrm{X} \\
\alpha_{1}+\alpha_{2} \mathrm{q}_{\mathrm{t}}=\mathrm{Y}_{\mathrm{t}} / \mathrm{X}_{\mathrm{t}}-\alpha_{0} / \mathrm{X}_{\mathrm{t}}-u_{t} / \mathrm{X}_{\mathrm{t}} & \text { (5) rearranged } \\
\left(d \mathrm{Y}_{\mathrm{t}} / d \mathrm{X}_{\mathrm{t}}\right)^{\text {True }}=\mathrm{Y}_{\mathrm{t}} / \mathrm{X}_{\mathrm{t}}-\alpha_{0} / \mathrm{X}_{\mathrm{t}}-u_{t} / \mathrm{X}_{\mathrm{t}} & \text { From (4) and (6) }
\end{array}
$$

If an estimate for $\alpha_{0}$ could be found, then it could be used to calculate a separate slope estimate for each observation using equation (8). The error due to such a procedure is shown in equation (9). The $u_{t} / \mathrm{X}_{\mathrm{t}}$ term in equation (9) should be extremely small because random error, $u_{t}$, is usually tiny relative to the size of $\mathrm{X}_{\mathrm{t}}$, making $u_{t} / \mathrm{X}_{\mathrm{t}}$ even smaller. This implies that the accuracy of calculating a separate slope estimate for each observation using equation (8) depends primarily upon the accuracy of the $\alpha_{0}$ estimate.

$$
\begin{aligned}
& \left(d \mathrm{Y}_{\mathrm{t}} / d \mathrm{X}_{\mathrm{t}}\right)^{\wedge}=\mathrm{Y}_{\mathrm{t}} / \mathrm{X}_{\mathrm{t}}-\alpha_{0} \wedge / \mathrm{X}_{\mathrm{t}} \\
& \left(d \mathrm{Y}_{\mathrm{t}} / d \mathrm{X}_{\mathrm{t}}\right)^{\text {True }}-\left(d \mathrm{Y}_{\mathrm{t}} / d \mathrm{X}_{\mathrm{t}}\right)^{\wedge}=\left(\alpha_{0} \wedge-\alpha_{0}\right) / \mathrm{X}_{\mathrm{t}}-u_{t} / \mathrm{X}_{\mathrm{t}} \text { From (7) and (8) }
\end{aligned}
$$

Inoue et. al. (2018) explore three ways to obtain an estimate for $\alpha_{0}$ : they are (I) using Ordinary Least Squares to estimate equation (1), (II) using Generalized Least Squares to estimate equation (1), and (III) using Bi-Directional Reiterative Truncated Projected Least Squares (BD-RTPLS) which produces separate slope estimates for layers of the data by peeling the data down layer by layer and then peeling the data up after which equation (10) is used with the resulting layer slopes to estimate $\alpha_{0}$. Leightner and Inoue (2012b) explain the math that underlies BD-RTPLS.

$$
\left(d \mathrm{Y}_{\mathrm{t}} / d \mathrm{X}_{\mathrm{t}}\right)^{\wedge}-\mathrm{Y}_{\mathrm{t}} / \mathrm{X}_{\mathrm{t}}=-\mathrm{a}_{0} \wedge / \mathrm{X}_{\mathrm{t}} \quad \text { (8) rearranged }
$$


Inoue et al (2018) show that when the omitted variable problem is ignored by estimating equation (1) using OLS, the resulting estimate for $\beta_{1}$ is approximately $a_{1}+a_{2} E\left[q_{t}\right]$ which leaves an "error" for the $t=i^{\text {th }}$ observation of approximately $a_{2} X_{i}\left(q_{i}-E\left[q_{i}\right]\right)+u_{i}$. The three methods of correcting for the omitted variables problem explored by Inoue et. al. (2018) would be better than ignoring the omitted variables problem if $\left|\left(\alpha_{0} \wedge-\alpha_{0}\right) / X_{i}-u_{i} / X_{i}\right|$ is less than $\left|\alpha_{2}\left\{q_{i}-E\left[q_{i}\right]\right\}\right|$. Aitken (1935) implies that the GLS estimate of $\alpha_{0}$ will be the Best Linear Unbiased Estimate (BLUE) if the $\mathrm{q}_{i}$ s are i.i.d. $\mathrm{N}\left(\mu_{\mathrm{q}}, \sigma_{\mathrm{q}}{ }^{2}\right)$ because GLS is BLUE for heteroscedastic models and Inoue et.al (2018) show that equation (3) is a heteroscedastic model if $\mathrm{q}_{\mathrm{i}}$ is unknown.

Inoue et al (2018) test the three methods using simulations (Leightner 2015 and Leightner and Inoue 2012b also provide simulation tests but solely for BD-RTPLS). Inoue et al (2018) run sets of 5,000 simulations each for the 27 combinations of 100 observations, 250 observations, and 500 observations with the omitted variable making a 1,000 percent difference to the slope, a 100 percent difference to the slope, and a 10 percent difference to the slope, and with random error being zero, one percent, and ten percent. Inoue et al (2018) gives the name "Variable Slope Ordinary Least Squares" (VSOLS) to the process of using OLS to estimate $\alpha_{0}$ which is then plugged into equation (8) to generate a separate slope estimate for each observation and the name "Variable Slope Generalized Least Squares" (VSGLS) to the process using GLS to estimate $\alpha_{0}$ which is then plugged into equation (8).

VSGLS and BD-RTPLS noticeably out performed VSOLS in all simulations. VSGLS and BD-RTPLS outperformed using OLS while ignoring the omitted variables problem except for the case where the omitted variable makes only a ten percent difference to the slope and random error is ten percent. When the importance of the omitted variable was 100 times as big as random error, using OLS while ignoring omitted variables produced approximately 35 times the error of both VSGLS and BD-RTPLS. When the importance of the omitted variable was 10 times as big as random error, then using OLS while ignoring omitted variables produced approximately 3.8 times the error of both VSGLS and BD-RTPLS. When there was no random error, then BD-RTPLS produced less than half the error of VSGLS. ${ }^{2}$ This last result implies that, since VSGLS is BLUE, BD-RTPLS must be better than BLUE when there is no random error which is reasonable if

\footnotetext{
2 When the omitted variable made a thousand percent difference to the slope and random error was only one percent, then the VSGLS error to BD-RTPLS error ratio was 1.57 when 100 observations were used, 1.15 when 250 observations were used, and 0.68 when 500 observations were used
} 
BD-RTPLS is better at capturing non-linear aspects of the data. Published applications of BD-RTPLS include Leightner, 2015, 2013, 2011a, 2011b, 2010a, 2010b, 2008, 2007, 2005a, 2005b, 2002 and Leightner and Inoue, 2012a, 2012b, 2009, 2008a, 2008b, and 2007. The next section of the paper uses BD-RTPLS to estimate the percentage change in inflation due to a one percent decrease in unemployment (the Phillips Curve) for 34 OECD countries between 2002 and 2017.

BD-RTPLS can only estimate positive relationships, and the Phillips curve shows a negative relationship between inflation and unemployment. To change this negative relationship into a positive one, the dependent variable (inflation rate) was multiplied by the negative one and then a constant was added to all observations so that they would become positive. This process changes the negative slope into a positive one without changing the absolute value of the slope (Leightner, 2015).

\section{The Empirical Results}

Figure 1 plots the percentage change in the consumer price index versus the unemployment rate for the USA between 2002 and 2017. From this figure, it looks as if the US Phillips curve shifted to the right from 2002 to 2003-2005, shifted left for 2006-2007, shifted back right for 2008-2009, shifted further right for 2010-2011, then shifted progressively further left each year for 2012, 2013, 2014, and 2015, and then was perhaps stable for 2015-2017 (or the actual Phillips curve for these last three years may have had a flatter shape and been annually shifting right). A similar diagram could be constructed for each country in my data. What Figure 1 clearly shows is that the US's Phillips curve often shifts and that factors that could cause those shifts should be included in any traditional estimation of the US's Phillips curve. Furthermore several of these shifts are contrary to what one would expect if solely inflation expectations (which are strongly affected by current inflation) were causing shifts. For example, the inflation rate for 2005 was noticeably higher than it was in 2002-2004, yet the 2006-2007 Phillips curve appears to shift left (not the expected shift right) in 2006. In 2009, the US consumer price index showed deflation which should cause the Phillips curve to shift left, instead it clearly shifted right. In 2011 the US inflation rate was higher than it had been in 2009 and 2010, yet the Phillips curve appears to shift left in 2012, contrary to expectations. Clearly either (1) more than just inflation expectations shift the Phillips curve or (2) the current inflation rate has very little impact on expectations for future inflation. Although Figure 1 clearly shows that the US's Phillips curve is shifting, it is possible to draw annual Phillips curves through Figure 1's data which have similar slopes; in other words, for which the percentage change in inflation due to a one percent decline in unemployment was relatively stable. 
The BD-RTPLS estimates for $d$ (inflation rate)/d(unemployment rate) are given in Table 1 and graphically depicted in Figures 2 and 3 (notice the difference in the y-axis scale between Figures 2 and 3). The gaps in Table 1 (and in Figures 2 and 3) for Mexico, Sweden, Switzerland, and Turkey are due to OECD not reporting unemployment or labor force data for those countries in those years. Ninety nine percent confidence intervals were constructed by using the Central Limit Theorem (Equation 11) applied to a given estimate and the two estimates before and the two estimates after it for a given country where " $s$ " is the standard deviation, " $n$ " is the number of observations and " $t$ " is from the Student's T Table.

Confidence interval $=$ mean $\pm(s / \sqrt{ } n) t_{n-1, a / 2}$

Each estimate (except for the first two and the last two estimates for a given country) will have its own confidence interval. This confidence interval implies that a researcher can be 99 percent confident that the next estimate will lie in that interval if omitted variables fluctuate no more than they recently have fluctuated (Leightner 2015). Furthermore, if this confidence interval includes zero, then we cannot be 99 percent confident that there is a relationship between the inflation rate and the unemployment rate. Only Iceland in 2008-2009 had a 99 percent confidence interval that contained zero. Thus all estimates, except those for Iceland in 2008 and 2009, given in Table 1 are significantly different from zero at a 99 percent confidence level.

As Table 1 shows, Australia's percentage change in inflation due to a one percent fall in unemployment was 4.03 in 2002. This implies that if Australia had reduced unemployment (via fiscal, monetary, trade, or exchange rate policy) by one percent in 2002 then inflation would have increased by 4.03 percent. Several observations are in order. First, there are noticeable differences in the level of $d$ (inflation rate)/d (unemployment rate) for different countries in different years. For example, in $2017 d$ (inflation rate)/d (unemployment rate) ranged from 1.27 for Greece to 10.01 for Japan. Secondly $d$ (inflation rate)/d (unemployment rate) changed over time for all countries. The country with the smallest standard deviation for $d$ (inflation rate)/d (unemployment rate) over time was Belgium and even her $d$ (inflation rate)/d (unemployment rate) varied from 3.07 to 3.74. The country (other than Iceland) with the highest standard deviation for $d$ (inflation rate)/d (unemployment rate) was the Netherlands for whom $d$ (inflation rate)/d (unemployment rate) varied from 12.66 to 3.70. The inflation cost of reducing unemployment by one percent going from 12.66 percent inflation to 3.70 percent inflation is massive. Even the USA's inflation to unemployment tradeoff more than doubled from 2.80 in 2010 to 6.09 in 2017. 
One of the most noticeable patterns in Figures 2 and 3 is that, even though the level for $d$ (inflation rate)/d (unemployment rate) varied noticeably from country to country, this tradeoff tended to move in similar directions for different countries. For example, the percentage change in inflation due to a one percent fall in unemployment declined in 2009 for thirty countries and rose in that year for only four countries - Belgium, Germany, Latvia, and Luxembourg. Apparently the global context for any given country has a noticeable effect on whether the tradeoff between inflation and unemployment is rising or falling, and this is true for the vast majority of countries. This result dovetails with Dumičićs (2017, p. 95 and 104) view that financial instability can be and has been a global phenomenon. Furthermore, some of the countries with the lowest inflation to unemployment tradeoffs in 2009 were countries most hurt by the Great Recession - Greece (2.86), Iceland (2.47), Ireland (2.79), and Spain (1.62). Japan, whose inflation to unemployment tradeoff was always noticeably higher than the mean tradeoff, has struggled with increasing inflation since the 1990s.

\section{Conclusion}

As long as countries continue to use fiscal, monetary, trade, and exchange rate policies in order to improve their economies, the tradeoff between inflation and unemployment will be extremely important. Countries need to know how their efforts to reduce unemployment will affect inflation and vice versa. However estimating this tradeoff using traditional statistical methods would require creating structural models that capture everything that can shift the short run aggregate supply and aggregate demand curves including changes in technology, cost of inputs, transportation costs, the environment (including weather, infrastructure, and institutions), fiscal policy, monetary policy, trade policy, exchange rates, income distribution, attitudes towards debt, producer and consumer expectations on growth, inflation, employment, income, and profits, etc. Even if such a model could be constructed, economists would disagree on the adequacy of its specification and complexity. This paper used a technique that captures the influence of omitted variables without having to find proxies or instruments for them and without having to construct a structural model. This technique produces a separate slope estimate for every observation. Variations in these slope estimates are due to omitted variables. Using this technique, I find inflation versus unemployment tradeoffs that are reasonable. These estimated tradeoffs are reduced form estimates (total derivatives) that capture all the ways that inflation and unemployment are related. They are NOT partial derivatives that show the effects on inflation of a change in unemployment holding everything else constant. These 
estimates should be helpful to governments trying to formulate optimal policy combinations.

Fabris (2018, p. 7) says, "There are no trade-offs between inflation and unemployment...There is no longer theoretical or empirical evidence nowadays to confirm the existence of a long-term trade-off between inflation and economic growth. Any potential use of trade-offs could only bring more uncertainty regarding inflation in the future." This paper confirms Fabris' (2018) view that there is no stable value for the percent change in inflation due to a one percent change in unemployment. However, this paper presents a technique that can estimate how that tradeoff is evolving which resurrects the usefulness of that trade-off. 


\section{References}

1. Akerlof, George A., William T. Dickens, George L. Perry, Truman F. Bewley, and Alan S. Blinder (2000). Near Rational Wage and Price Setting and the Long-run Phillips Curve. Brookings Papers in Economic Activity, 2000(1); $1-60$.

2. Cogley, Timothy and Argia M. Sbordone (2008). Trend Inflation, Indexation, and Inflation Persistence in the New Keynesian Phillips Curve. American Economic Review 98(5); 2101-2126.

3. Debelle, Guy and Douglas Laxton (1997). Is the Phillips curve really a curve? Some evidence for Canada, the United Kingdom, and the United States. IMF Staff Papers, 44(2); 249-282.

4. Dolado, Juan J., Ramon Maria-Dolores, and Manuel Naveira (2005). Are Monetary Policy Reaction Functions asymmetric?: The Role of Nonlinearity in the Phillips Curve. European Economic Review 49(2); 485-503.

5. Dumičić, Mirna (2017). A Brief Introduction to the World of Macroprudential Policy. Journal of Central Banking Theory and Practice (1), 87-109.

6. Fabris, Nikola (2018). Challenges for Modern Monetary Policy. Journal of Central Banking Theory and Practice (2), 5-24.

7. Gali, Jordi, Mark Gertler, and David Lopez-Salido (2005). Robustness of the Estimates of the Hybrid New Keynesian Phillips Curve. Journal of Monetary Economics 52(6); 1107-1118.

8. Inoue, Tomoo, Pierre Lafaye de Micheaux, and Jonathan Leightner (2018). Several Related Methods of Estimating Total Derivatives that Capture the Influence of Omitted Variables. Manuscript.

9. Lakić, Slobodan, Damir Šehović, and Mimo Drašković (2016). Relevance of Low Inflation in the Southeastern European Countries. Journal of Central Banking Theory and Practice (2), 41-63.

10. Leightner, Jonathan E. (2015). The Limits of Fiscal, Monetary, and Trade Policies: International Comparisons and Solutions. Singapore: World Scientific.

11. Leightner, Jonathan E. (2013). The Diminishing Returns to Accumulating Foreign Reserves: Implications for China, the USA, and the World. China Economic Policy Review 2(1) 25 pages DOI: 10.1142/S1793969013500040.

12. Leightner, Jonathan E. (2011a). Chinese Overtrading. In Steven Rosefielde, Masaaki Kuboniwa, and Satoshi Mizobata (Eds.), Two Asias: The Emerging Postcrisis Divide. Singapore: World Scientific Publishers.

13. Leightner, Jonathan E. (2011b). Fiscal Stimulus for the US in the Current Financial Crisis: What does 1930-2008 tell us? Applied Economic Letters 18(6), 539-549. 
14. Leightner, Jonathan E. (2010a). China's Fiscal Stimulus Package for the Current International Crisis: What does 1996-2006 tell us? Frontiers of Economics in China 5(1), 1-24.

15. Leightner, Jonathan E. (2010b). How China's Holdings of Foreign Reserves Affect the Value of the US dollar in Europe and Asia. China \& World Economy 18(3), 24-39.

16. Leightner, Jonathan E. (2008). Omitted Variables and how the Chinese Yuan affects other Asian Currencies. International Journal of Contemporary Mathematical Sciences 3(14), 645-666.

17. Leightner, Jonathan E. (2007). Omitted Variables, Confidence Intervals, and the Productivity of Exchange Rates. Pacific Economic Review 12(1), 15-45.

18. Leightner, Jonathan E. (2005a). Fight Deflation with Deflation, not with Monetary Policy. The Japanese Economy: Translations and Studies 33(2), 6793.

19. Leightner, Jonathan E. (2005b). The Productivity of Government Spending in Asia: 1983-2000. Journal of Productivity Analysis 23, 33-46.

20. Leightner, Jonathan E. (2002). The Changing Effectiveness of Key Policy Tools in Thailand. Institute of Southeast Asian Studies for East Asian Development Network, EADN Working Paper \# 19(2002) x0219-6417.

21. Leightner, Jonathan E. and Tomoo Inoue (2012a). Is China replacing the USA as an Engine for Global Growth? International Economics \& Finance Journal 7(1), 55-77.

22. Leightner, Jonathan E. and Tomoo Inoue (2012b). Solving the Omitted Variables Problem of Regression Analysis using the Relative Vertical Position of Observations. Advances in Decision Sciences available at $h t t p: / /$ www.hindawi.com/journals/ads/2012/728980/.

23. Leightner, Jonathan E. and Tomoo Inoue (2009). Negative Fiscal Multipliers Exceed Positive Multipliers during Japanese Deflation. Applied Economic Letters 16(15), 1523-1527.

24. Leightner, Jonathan E. and Tomoo Inoue (2008a). Capturing Climate's Effect on Pollution Abatement with an Improved Solution to the Omitted Variables Problem. European Journal of Operational Research 191(2), 539556.

25. Leightner, Jonathan E. and Tomoo Inoue (2008b). The Effect of the Chinese Yuan on other Asian Currencies during the 1997-1998 Asian Crisis. International Journal of Economic Issues 1(1), 11-24.

26. Leightner, Jonathan E. and Tomoo Inoue (2007). Tackling the Omitted Variables Problem without the Strong Assumptions of Proxies. European Journal of Operational Research 178(3), 819-840. 
27. Mankiw, N. Gregory and Ricardo Reis (2002). Sticky Information versus Sticky Prices: A Proposal to Replace the New Keynesian Phillips Curve. Quarterly Journal of Economics 117(4); 1295-1328.

28. Roberts, John M. New Keynesian Economics and the Phillips Curve. Journal of Money, Credit, and Banking 27(4); 975-984.

29. Rudd, Jeremy and Karl Whelan (2005). New Tests of the New Keynesian Phillips Curve. Journal of Monetary Economics 52(6); 1167-1181.

30. Samuelson, Paul A and Robert M. Solow (1960). Analytical Aspects of AntiInflation Policy. American Economic Review: Papers and Proceedings of the Seventy Second annual meeting of the American Economic Association, 50(2); 177-194. 


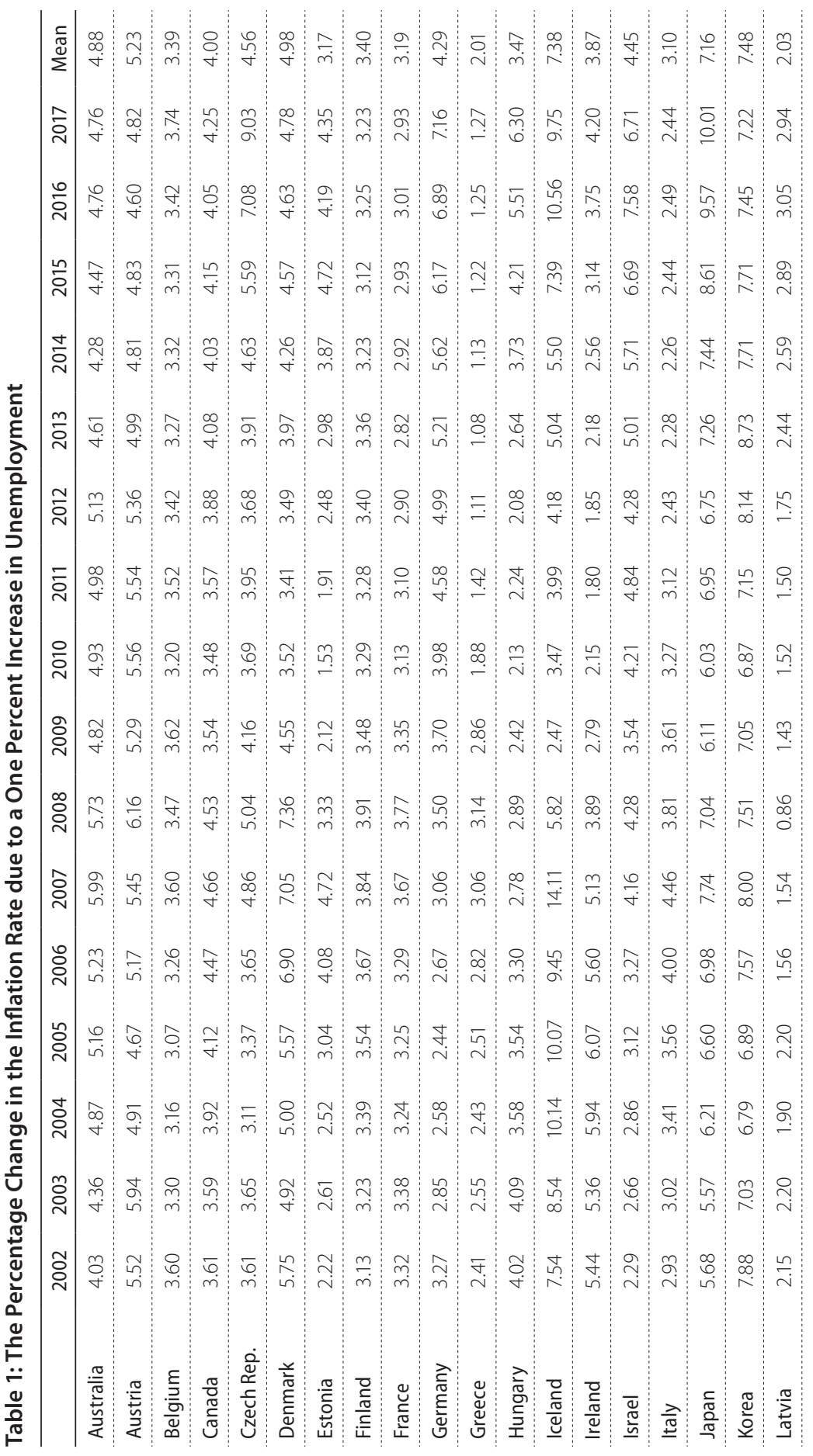




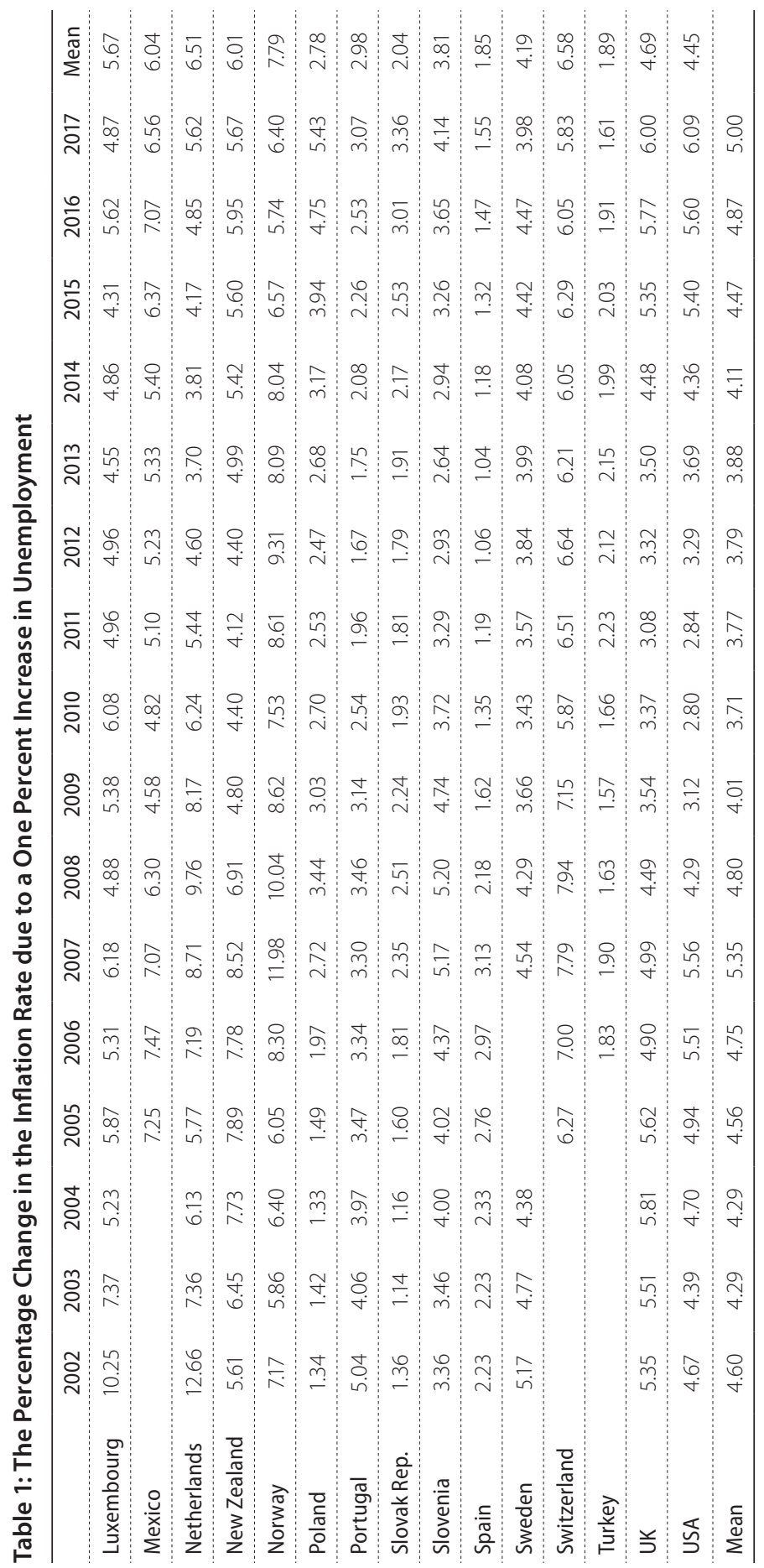


Figure 1: Inflation versus Unemployment in the USA

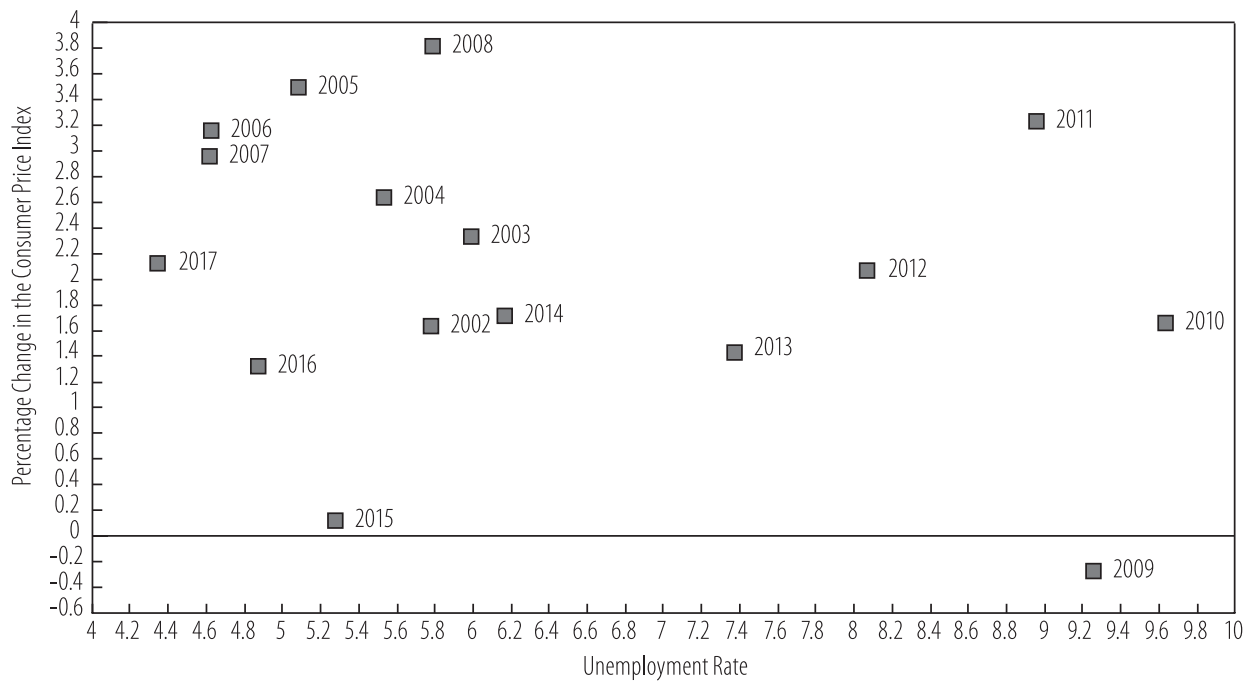

Figure 2: The Percentage Change in Inflation Due to a One Percent Decrease in Unemployment Non-European Countries

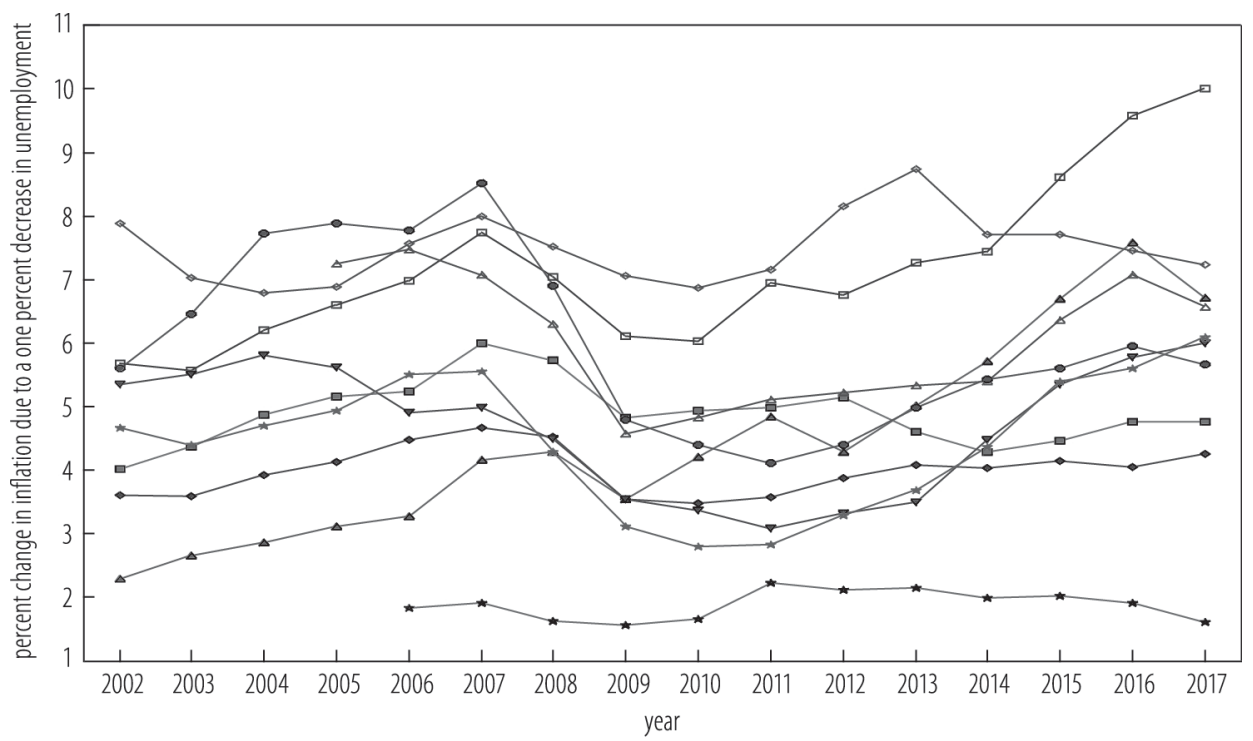
$\because$ Australia
$\Delta$ |srael
в Japan
$\Leftrightarrow$ Korea
$\star$ Mexico
- New Zealand * Turkey
* United Kingdom * United States 
Figure 3: The Percent Change in Inflation due to a One Percent Decrease in Unemployment European Countries

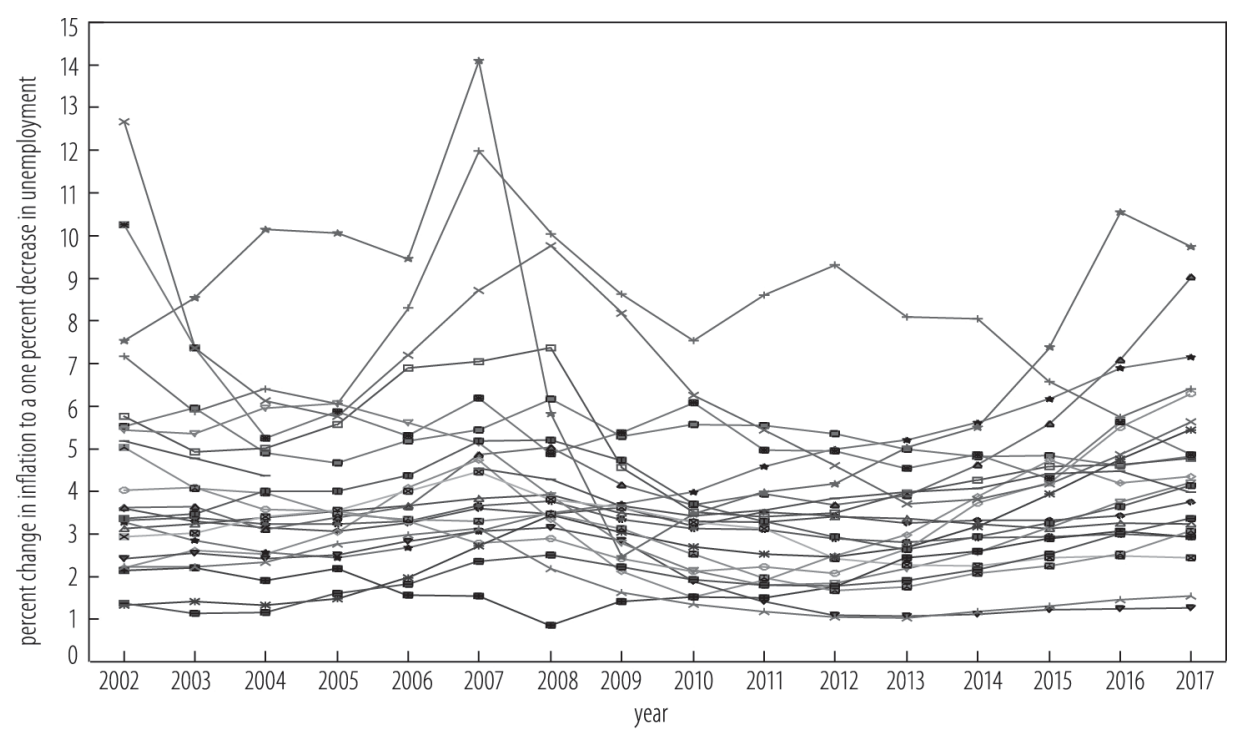

- Austria Belgium $\Delta$ Czech $\quad$ Denmark $\Leftrightarrow$ Estonia $\star$ Finland $\bullet$ France $\star$ Germany $\nabla$ Greece $\ominus$ Hungary $\star$ Iceland $\nabla$ Ireland

x Italy $\mathbf{m}$ Latvia $\mathbf{*}$ Luxembourg * Netherland + Norway * Poland $\mathbf{x}$ Portugal $\mathbf{m}$ Slovakia $\mathbf{m}$ Slovenia $\star$ Spain - Sweden 